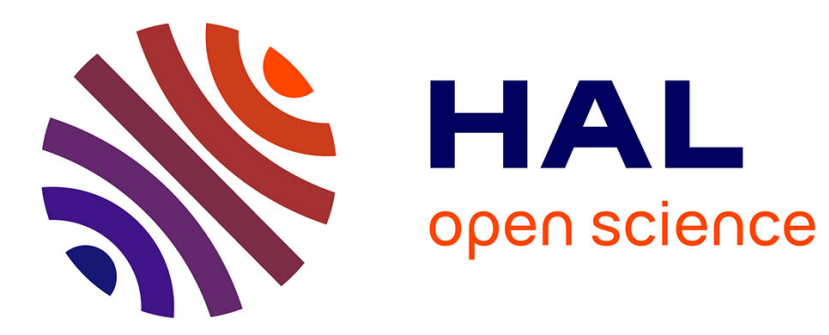

\title{
Convergence in Household Credit Demand Across Euro Area Countries: Evidence from Panel Data
}

\author{
Olivier R de Bandt, Catherine Bruneau, Widad El Amri
}

\section{To cite this version:}

Olivier R de Bandt, Catherine Bruneau, Widad El Amri. Convergence in Household Credit Demand Across Euro Area Countries: Evidence from Panel Data. Applied Economics, 2009, 41 (27), pp.34473462. 10.1080/00036840701493774 . hal-00582203

\section{HAL Id: hal-00582203 https://hal.science/hal-00582203}

Submitted on 1 Apr 2011

HAL is a multi-disciplinary open access archive for the deposit and dissemination of scientific research documents, whether they are published or not. The documents may come from teaching and research institutions in France or abroad, or from public or private research centers.
L'archive ouverte pluridisciplinaire $\mathbf{H A L}$, est destinée au dépôt et à la diffusion de documents scientifiques de niveau recherche, publiés ou non, émanant des établissements d'enseignement et de recherche français ou étrangers, des laboratoires publics ou privés. 


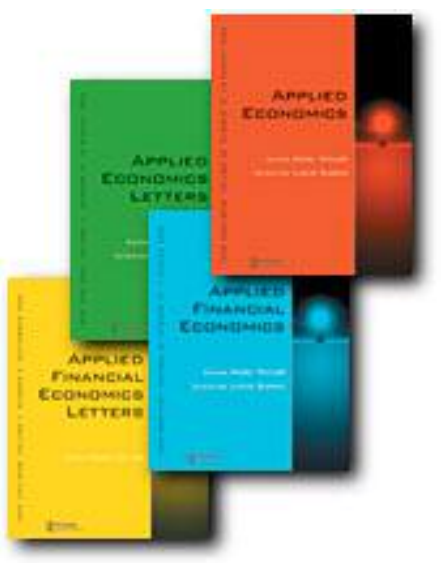

Convergence in Household Credit Demand Across Euro Area Countries: Evidence from Panel Data

\begin{tabular}{|c|l|}
\hline Journal: & Applied Economics \\
\hline Manuscript ID: & APE-06-0764 \\
\hline Journal Selection: & Applied Economics \\
\hline JEL Code: & $\begin{array}{l}\text { E51 - Money Supply } \mid \text { Credit|Money Multipliers < E5 - Monetary } \\
\text { Policy, Central Banking, and the Supply of Money and Credit < E - } \\
\text { Macroeconomics and Monetary Economics, C31 - Cross-Sectional } \\
\text { Models/Spatial Models < C3 - Econometric Methods: } \\
\text { Quantitative Methods, C32 - Time-Series Models < C3 - } \\
\text { Econometric Methods: Multiple/Simultaneous Equation Models < C - } \\
\text { Mathematical and Quantitative Methods, C33 - Models with Panel } \\
\text { Data < C3 - Econometric Methods: Multiple/Simultaneous Equation } \\
\text { Models < C - Mathematical and Quantitative Methods }\end{array}$ \\
\hline Keywords: & $\begin{array}{l}\text { Credit demand, panel cointegration, households, bank profitability, } \\
\text { euro area }\end{array}$ \\
\hline
\end{tabular}

\section{S ScholaroNE \\ Manuscript Central}




\title{
Convergence in Household Credit Demand Across Euro Area Countries: Evidence from Panel Data*
}

\author{
O. de Bandt $\dagger$ C. Bruneau $\ddagger$ W. El Amri ${ }^{\S}$
}

(This Version: October 2006)

\begin{abstract}
This paper contributes to the literature on the convergence of financial systems in the euro area by estimating household credit demand in individual countries. Using the ARDL framework advocated notably by Pesaran et al. (1999), the paper provides evidence on the convergence of long run credit demand determinants (interest rates, investment and house prices) in the largest euro area countries, while short run dynamics remain heterogenous across countries. The paper also demonstrates that the equation uncovers demand rather than supply behaviour. Keywords : Credit demand, panel cointegration, households, bank profitability. JEL classification: E51, C31, C32, C33.
\end{abstract}

\footnotetext{
*Any views expressed in this paper are the authors' own and do not necessarily reflect those of the Banque de France or the Eurosystem.

${ }^{\dagger}$ Banque de France, corresponding author. E-mail: olivier.debandt@banque-france.fr address: Banque de France, 46-1405 DAMEP, 39 rue croix des petits champs, 75049 Paris Cedex 01, France, Tel.: +33 142 9228 80, Fax: + 33142924950 .

${ }^{\ddagger}$ Banque de France and University of Paris X, EconomiX.

${ }^{\S}$ Banque de France and University of Paris X, EconomiX.
} 


\section{Introduction}

In the euro area, credit dynamics play an important role in the transmission of the Single Monetary Policy. As opposed to the "money view", where the transmission channels of monetary policy are based on the direct effect of interest changes on household and corporate spending, the "credit view" argues that if financial markets are incomplete or imperfect, it is important to consider the availability of external credit, which may amplify the previous transmission channels of monetary policy (Bernanke, 1988). This is all the more important in the euro area since banks are the main providers of funds to households and companies (ECB, 2002). In addition, while money markets are harmonized, credit markets remain, to a certain extent, segmented, due to differences in language, institutions and competitive environment (see Neven and Röller, 1999). The paper investigates household credit demand in the euro area and the extent to which it displays similar patterns across countries. Indeed, it is interesting to assess whether the introduction of EMU has changed the functioning of credit markets. Special attention is also devoted to the response of credit demand to house prices, which have significantly increased in many countries since the mid-1990s.

An obvious limitation to the traditional time series approach applied to the analysis of credit markets (Friedman and Kuttner, 1993, Fase, 1995) is the lack of long time series of observations. Extending the analysis to a panel of euro area countries may overcome such difficulties and we rely on recent papers in international economics that have addressed the issue of cross-country comparisons, with a view to accommodating the heterogeneity between individuals/countries in panels.

We estimate a long run relationship which characterizes the relationship between household credit in the euro area (in real terms) and investment, interest rate, as well as house prices as fundamentals. The analysis focuses on nine euro area countries for which sufficiently long quarterly time series are available. We examine whether it is possible to find an homogeneous long run relationship, with common coefficients for all countries, but we allow for specific short run dynamics, using the ARDL (AutoRegressive Distributed Lags) model proposed by Pesaran et al. (1999). The intuition is that short run dynamics are more likely to be affected by institutional factors that differ across countries, while long run evolutions are driven by similar economic determinants. Anticipating the results, the paper shows that the household credit variable in euro area countries exhibits similar patterns in the long run, but that it can only be interpreted as a cointegration relationship in the largest countries, while the stability of short run dynamics indicates that differences persist over the sample period.

Such a class of models describes the dynamics of a series according to a single equation approach, where the change in the selected endogenous variable (here, real household credit outstanding) is determined by the first lag of the error-correction mechanism associated with a long run relationship, by its own past first differences and by the current and past first differences of the (assumed) exogenous variables.

For a long run relationship to exist we require two properties: first, its error-correction coefficient in the ARDL equation is significant for (almost) all individuals (countries); 
second, at least one of the fundamentals must have a significant coefficient in this relation. To investigate these two properties, we use the "bounds tests" proposed by Pesaran et al. (2001) for time series.

It is worth emphasizing that the ARDL framework does not provide a test for cointegration taking advantage of the panel dimension. We refer therefore to the procedure suggested by Kao (1999) for investigating whether the long run relationship estimated in the ARDL framework can be recognized as a cointegration relationship.

The paper is organized as follows. In section 2, we propose a brief survey of credit demand analysis and describe the data we use. Section 3 discusses the interest of ARDL models. In section 4 , we briefly recall how to validate the existence of long run relationships using panel cointegration tests and "bounds tests". Section 5 presents the empirical results. Section 6 addresses the robustness of results and in particular whether one really identifies a demand as opposed to a supply schedule. Section 7 concludes.

\section{Structural Analysis of Credit Markets and data sources}

We provide here a quick overview of the literature on equilibrium on the credit market, with exclusive focus on credit to households. A standard reference is the paper by Friedman and Kuttner (1993), who identify supply and demand of loans to the private sector in the United States. The workhorse of the literature is the estimation of a credit demand relationship defined as $D_{t}^{d}=f\left(R_{t}, \varepsilon_{t}\right)$, where $D_{t}$ is loan volume (i.e. in real terms, after applying a price deflator), $R_{t}$ is the interest rates and $\varepsilon_{t}$ represents the set of demand variables, including aggregate wealth, disposable income (which can be viewed as a proxy for wealth), investment and cost variables. The demand for credit is proportional to these variables. Another variable that is often considered in the credit literature is inflation, which measures additional costs and has a positive effect on credit demand. For household credit, relative house prices (i.e. house prices divided by the private consumption deflator) are equally introduced as a proxy for wealth. Its effect on loan demand is either direct, measuring the cost of housing (higher house prices also improve the value of the collateral pledged against new credit), or indirect because of the effect of higher consumption (associated with higher wealth) on consumption credit. Wealth effects have long been considered as a major factor behind credit cycles (Iacoviello, 2005, as well as Kiyotaki and Moore, 1997, for a modern version of Fisher's (1933) debt deflation theory). In addition, demand is negatively affected by interest rates: $\frac{\partial D^{d}}{\partial R}<0 .{ }^{1}$ Considering such an equation, one can obviously draw a parallel with the literature on money demand.

When dealing with credit markets, this equation is often complemented with a credit supply equation, which introduces risk factors and variables measuring banks' profitability. The latter is written as $D_{t}^{s}=f\left(R_{t}, \varepsilon_{t}\right)$, where $\frac{\partial D^{d}}{\partial R}>0$ (see Neven and Röller, 1999, among others);

Such an approach is also used by Fase (1995) for the Netherlands, although the author

\footnotetext{
${ }^{1}$ Another issue is whether one should consider real or nominal interest rates, but the debt burden depends on nominal interest rates.
} 
focuses on credit demand, assuming that the stock of credit is mainly determined by the demand side of the market. De Greef and de Haas (2000) for the Netherlands and Gimeno and Martinez-Carrascal (2006) for Spain include disposable income and real house prices in the demand for credit and consider the joint dynamics of house prices and mortgage loans. Hofmann (2001) investigates such a system for a set of OECD countries. It is beyond the scope of the current paper to estimate such a joint system, in particular because many other variables affect house prices, notably through demographic developments.

We focus on credit demand and look for a robust estimation method of a single equation, as in Calza et al. (2003), but instead of looking directly at euro area aggregates like these authors do, we take advantage of the panel dimension.

Indeed, the identification of a demand equation from data is problematic because demand and supply factors operate jointly and implicitly influence the series which are observed. Even if one finds a negative estimate of the elasticity of credit to interest rate, one cannot strictly conclude that one has estimated a credit demand equation. In that case, one can just claim that demand factors are working, while the equation might just be a reduced form including both supply and demand effects. One way forward is therefore to test whether the residuals of the regression of credit onto different demand-type fundamentals are not correlated with one (or several) proper supply factor(s). If it is the case, one can conclude that the regression really identifies a demand function.

Accordingly, we first estimate a credit function by estimating a long run equation and validate the existence of cointegration between the credit variable and demand-type fundamentals. Then, we look at the residuals of the regression and check that they are not correlated with indicators of bank profitability.

The database is described in further detail in Appendix A.1. It contains quarterly data on loans to households, private consumption deflator, investment, long-term interest rates and national house price indices. The source of data are Eurosystem quarterly monetary statistics for credit and the OECD Economic Outlook database for the macroeconomic series. House prices come from a database constructed by the Banque de France assembling homogenous data on prices of existing houses. Due to data availability, the database only covers the Q1 1991-Q4 2005 period and includes nine euro area countries (Portugal, Greece and Luxembourg are always excluded), but we also exclude Belgium and Austria for some part of the analysis, since these countries exhibit non-significant results. As a consequence, $N=7$ or 9 series over $T=60$ periods. All series are seasonally adjusted when necessary (this is only required for the credit series).

In what follows, we recall the main results obtained from panel data analysis to estimate long run relationships, by focusing first on the ARDL framework. 


\section{ARDL Models (Pesaran et al., 1999)}

ARDL models are widely used in the literature (see in particular Hendry et al., 1984), and its reparametrisation as an ECM is well established in the time series context (Bewley, 1979, Bardsen, 1989). ${ }^{2}$ The main interest of ARDL models is threefold: $(i)$ they provide a convenient way to deal with long run relationships by focusing on the dynamics of one single equation, where the long run relationship and the short run dynamic are estimated jointly; (ii) they can therefore be easily extended to a panel framework; (iii) they make it possible to deal with variables that are of different order of integration, namely $I(0)$ and $I(1)$, and not simply $I(1)$.

We focus on ARDL models for time-series before looking at these models for panel data.

\subsection{ARDL models for time series}

In the ARDL approach, by Pesaran and Shin (1999), one concentrates on one endogenous variable of interest, $Y$, or equivalently on one single equation:

$$
Y_{t}=a_{0}+a_{1} t+\sum_{j=1}^{p} \lambda_{j} Y_{t-j}+\sum_{j=0}^{q} \delta_{j}^{\prime} X_{t-j}+u_{t},
$$

where $X$ denotes the set of regressors, which are supposed to be non-correlated with the residuals $u$.

One often finds the equivalent specification: ${ }^{3}$

$$
\Delta Y_{t}=\phi Y_{t-1}+\beta^{\prime} X_{t}+\sum_{j=1}^{p-1} \lambda_{j}^{*} \Delta Y_{t-j}+\sum_{j=0}^{q-1} \delta_{j}^{* \prime} \Delta X_{t-j}+a_{0}+a_{1} t+u_{t} .
$$

The objective of this subsection is to recall the intuition behind the previous equation, and in particular, its link with VAR models and VECMs.

Starting from a VAR model for the $Z_{t}=\left(Y_{t}, X_{t}^{\prime}\right)^{\prime}$ vector, the system of equations is partitioned in order to obtain the single equation above. More precisely, as a start, one writes the (canonical) VAR model:

$$
\begin{aligned}
& \Phi(L)\left(Z_{t}-\mu-\gamma t\right)=\varepsilon_{t} \\
\Leftrightarrow \quad & \Delta Z_{t}=\alpha_{0}+\alpha_{1} t+\Pi Z_{t-1}+\sum_{i=1}^{p-1} \Gamma_{i} \Delta Z_{t-i}+\varepsilon_{t},
\end{aligned}
$$

Where $\alpha_{0}=-\Pi \mu+(\Gamma+\Pi) \gamma ; \Gamma=I d-\sum_{i=1}^{p-1} \Gamma_{i} ; \Pi=-\left(I d-\sum_{i=1}^{p} \Phi_{i}\right)$ and $\alpha_{1}=-\Pi \gamma$. $\Omega=\left[\begin{array}{cc}\omega_{y y} & \omega_{y x} \\ \omega_{x y} & \Omega_{x x}\end{array}\right]$ is the variance-covariance matrix of $\varepsilon_{t}$.

\footnotetext{
${ }^{2}$ See Banerjee et al. (1993).

${ }^{3}$ Here, the equivalence with equation (1) requires that $\phi=-\left(1-\sum_{j=1}^{p} \lambda_{j}\right)$ and $\beta=\sum_{j=0}^{q} \delta_{j}^{\prime} ; \lambda_{j}^{*}=$ $-\sum_{m=j+1}^{p} \lambda_{m}$ for $j=1,2, \ldots, p-1 ; \delta_{j}^{*}=-\sum_{m=j+1}^{q} \delta_{m}$ for $j=1,2, \ldots, q-1$.
} 
Thus, by separating the equation of $Y$ from those of the other components $X$, with the corresponding partition of the different matrices, one can write the $\Delta Y$-equation under the ECM type form:

$$
\Delta Y_{t}=c_{0}+c_{1} t+\pi_{y y} Y_{t-1}+\pi_{y x} X_{t-1}+\sum_{i=1}^{p-1} \Gamma_{y i} \Delta Z_{t-i}+\varepsilon_{y t},
$$

with $\Pi$ written as $\Pi=\left[\begin{array}{ll}\pi_{y y} & \pi_{y x} \\ \pi_{x y} & \Pi_{x x}\end{array}\right]$ and $\varepsilon_{t}=\left(\varepsilon_{y t}, \varepsilon_{x t}^{\prime}\right)^{\prime}$.

Finally, in order to orthogonalize the $\Delta Y$ and $\Delta X$ innovations, one introduces contemporaneous regressors $X$ in the $\Delta Y$-equation as following: ${ }^{4}$

$$
\Delta Y_{t}=c_{0}+c_{1} t+\pi_{y y} Y_{t-1}+\pi_{y x . x} X_{t-1}+\sum_{i=1}^{p-1} \Psi_{i}^{\prime} \Delta Z_{t-i}+\omega^{\prime} \Delta X_{t}+u_{t},
$$

where $\pi_{y x . x}=\pi_{y x}-\omega^{\prime} \Pi_{x x}($ matrix $1 \times k) ; \omega=\Omega_{x x}^{-1} \omega_{x y}$ and $u_{t}=\varepsilon_{y t}-\omega_{y x} \Omega_{x x}^{-1} \varepsilon_{x t}$. With $u_{t}$ i.i.d. $N\left(0, \omega_{u u}\right)$ and $\omega_{u u}=\omega_{y y}-\omega_{y x} \Omega_{x x}^{-1} \omega_{x y}$.

If $\phi=\pi_{y y}$ and $\beta=\pi_{y x . x}$, after redefining the lag polynominal in $Z$ in order to get the contemporaneous value of $X$ in the level part, this yields Pesaran's et al. (2001) single equation (2) of the ARDL approach:

$$
\Delta Y_{t}=c_{0}+c_{1} t+\pi_{y y} Y_{t-1}+\pi_{y x . x} X_{t}+\sum_{i=1}^{p-1} \widetilde{\Psi}_{i}^{\prime} \Delta Z_{t-i}+\omega^{\prime} \Delta X_{t}+u_{t} .
$$

By construction, innovations $u_{t}$ and $\varepsilon_{x t}$ (the canonical innovations of the $X$ variables in the canonical VAR model) are not correlated.

Pesaran et al. (2001) assume that $\left\{\pi_{x y}=0\right\}$. Such an assumption is equivalent to excluding the feedback of the level of $Y$ on the level of $X$, and to assuming that there exists at most one long run relationship with $Y$ as endogenous variable. One can refer to the example provided by Pesaran, Shin and Smith (2001), who study a wage equation where real wage is a function of labor productivity but the effect of the level of the real wage on productivity is excluded, consistently with bargain theory. One can also test for that constraint. Here we assume, in particular, that house prices are exogenous and that credit does not cause house prices. Such an assumption is consistent with Gouteron and Szpiro (2005), who indicate that excess credit does not explain house prices in the euro area, in opposition with the earlier conclusion by Hofmann (2001), but for aggregate private sector credit in the latter case.

It is worth emphasizing that the ARDL models have been introduced to avoid pretesting to ensure that all components of $Z$ are $I(1)$ as required by the VECM specification.

${ }^{4}$ It is equivalent to multiplying both members of the VAR specification by the matrix:

$$
P=\left[\begin{array}{cc}
1 & -\omega_{y x} \Omega_{x x}^{-1} \\
0 & I d
\end{array}\right]
$$


If $\phi \neq 0, \Pi$ has reduced rank $r+1(r \leq k$, the number of variables in $Z)$ and one can write a long run relation with $Y_{t}$ as endogenous variable as:

$$
Y_{t}=\theta_{0}+\theta_{1} t-\frac{1}{\phi} \beta^{\prime} X_{t}+v_{t}
$$

The long run relationship is non-degenerated if $\theta=-\frac{\beta}{\phi}$, the vector of long run parameters "conditional on" $X$, is non null (or equivalently, if $\beta \neq 0$ ).

If $X_{t}, Y_{t}$ are $I(1)$ and $v_{t}$ is $I(0)$, one can claim that $Y_{t}$ and $X_{t}$ cointegrate according to the conditional relationship. Thus $\phi$ characterizes the intensity of the "error-correction" mecanism. ${ }^{5}$

As already indicated, the coefficients associated with $X_{t}$, namely $\frac{\pi_{y x . x}}{\pi_{y y}}$, are not identical to the ones in the canonical VECM (i.e. $\left.\frac{\pi_{y x}}{\pi_{y y}}\right)$.

\subsection{Extension to panel data}

When the ARDL specification is used for panel data, a single equation is written for each individual $i$ :

$$
\Delta Y_{i t}=\phi_{i} Y_{i t-1}+\beta_{i}^{\prime} X_{i t}+\sum_{j=1}^{p-1} \lambda_{i j}^{*} \Delta Y_{i t-j}+\sum_{j=0}^{q-1} \delta_{i j}^{* \prime} \Delta X_{i t-j}+c_{0 i}+c_{1 i} t+u_{i t},
$$

$\forall 1 \leq i \leq N$ and $1 \leq t \leq T$.

The main assumptions required by the Pesaran et al.'s (1999) Pooled Mean Group model are as follows:

$\left(a_{1}\right)$ Residuals $u_{i t}$ are assumed to be independent across individuals and independent from regressors $X_{i t}$ (the latter hypothesis is just necessary to get consistent estimates of the short run parameters $\lambda_{i j}^{*}$ and $\delta_{i j}^{* \prime}$ ), but they may have different variances $\sigma_{i}^{2}=\operatorname{Var}\left(u_{i t}\right)$.

$\left(a_{2}\right)$ For each individual $i$, the long run relation:

$$
Y_{i t}=-\frac{\beta_{i}^{\prime}}{\phi_{i}} X_{i t}+v_{i t}
$$

corresponds to a cointegration relation, that is $v_{i t}$ is $I(0)$.

$\left(a_{3}\right)$ The long run coefficients $\theta_{i}=-\frac{\beta_{i}}{\phi_{i}}$ are the same for the different individuals under the long run homogeneity hypothesis:

$$
\forall i, \theta_{i}=-\frac{\beta_{i}}{\phi_{i}}=\theta
$$

\footnotetext{
${ }^{5} Y_{t}$ is $I(0)$, like $v_{t}$, if $\theta=0$, that is if $\pi_{y x}-\omega^{\prime} \Pi_{x x}=0$ with $\omega \neq 0$.
} 
(the short run parameters can differ from one individual to another). ${ }^{6}$

Assumption $\left(a_{1}\right)$ is often supposed to be satisfied without being tested. In the next section, we examine how to test this hypothesis by using the cointegration test proposed by Kao (1999) in a panel context, or the "bounds tests" procedure proposed by Pesaran et al. (2001) for time series analysis.

Assumption $\left(a_{3}\right)$ is usually tested by referring to an Hausman statistic measuring a distance between the estimator of the unconstrained model named Mean Group Estimator (where the long run parameters are free like the short run ones) and the estimator of constrained model named PMG estimator (under the long run homogeneity hypothesis). When there is no rejection, one concludes that there is long run homogeneity.

Now, the question is how to test these different assumptions and, among them, the cointegration hypothesis.

\section{Investigation of long run relationships from panel data}

In this section, we examine different approaches to validate the existence of a long run relationship for panel data. We first briefly recall the methodology proposed by Kao (1999) to test for cointegration by using a pooled procedure before examining how to exploit "bounds tests" on individuals countries (Pesaran et al., 2001).

\subsection{Cointegration tests along the lines of Kao (1999)}

In the Kao (1999) framework, one assumes that the long run parameters $\beta$ are the same for all individuals and allow heterogeneity through fixed effects. ${ }^{7}$ More precisely, the set-up is the following:

$$
\begin{gathered}
Y_{i t}=Z_{t}^{\prime} \gamma_{i}+X_{i t}^{\prime} \beta+e_{i t}, \\
Z_{t}^{\prime} \gamma_{i}=\left(\alpha_{i}+\delta_{i} t+\ldots\right), \\
X_{i t}=X_{i t-1}+\varepsilon_{i t},
\end{gathered}
$$

where $\varepsilon_{i t}$ is $i . i . d$; accordingly, the variables $\left(Y_{i t}, X_{i t}\right)$ are supposed to be independent for different individuals. In what follows, the deterministic part is supposed to be reduced to a constant $\left(Z_{t}=1\right)$.

Kao (1999) considers the estimation of $\beta$ with the least squared dummy variable (LSDV) estimator:

$$
\widehat{\beta}=\left[\sum_{i=1}^{N} \sum_{t=1}^{T} \widetilde{X}_{i t} \tilde{X}_{i t}^{\prime}\right]^{-1}\left(\sum_{i=1}^{N} \sum_{t=1}^{T} \tilde{X}_{i t} \widetilde{Y}_{i t}\right),
$$

\footnotetext{
${ }^{6}$ The long-term coefficients are estimated by maximisation of a concentrated likelihood function, through an iterative procedure ("Newton-Raphson" or "back-substitution" algorithm), introducing the $\theta_{i}, \phi_{i}$ and $\sigma_{i}^{2}$ coefficient (pooled estimation). Using the estimated $\widehat{\theta}_{i}$ coefficients (as derived from the previous algorithms), the short run coefficients (including the $\phi_{i}, \sigma_{i}^{2}$ and the intercepts) are then estimated separately for each country by OLS. The PMG estimator for the short run coefficients is the average over all countries.

${ }^{7}$ This formulation is less restrictive than a Pooled model which specifies constant coefficients.
} 
with $\tilde{Y}_{i t}=M_{\{\mathcal{Z}\}} Y_{i t}$ and $\widetilde{X}_{i t}=M_{\{\mathcal{Z}\}} X_{i t}$ (Frisch-Waugh). ${ }^{8}$

The cointegration tests, in the panel context, are thus Unit Root tests on the estimated residuals:

$$
\widehat{e}_{i t}=\widetilde{Y}_{i t}-\widetilde{X}_{i t}^{\prime} \widehat{\beta}
$$

By implementing the following regressions :

$$
\begin{gathered}
\widehat{e}_{i t}=\rho \widehat{e}_{i t-1}+v_{i t} \\
\text { and } \widehat{e}_{i t}=\rho \widehat{e}_{i t-1}+\sum_{j=1}^{p} \varphi_{j} \triangle \widehat{e}_{i t-j}+v_{i t p},
\end{gathered}
$$

Kao (1999) tests the null hypothesis of non-cointegration, namely $H_{0}: \rho=1$, against $H_{1}$ : $\rho<1$, and suggests from (A), four Dickey-Fuller type statistics $\left(D F_{\rho}, D F_{t}, D F_{\rho}^{*}\right.$ and $\left.D F_{t}^{*}\right)$ and from (B), an Augmented Dickey-Fuller type statistic $\left(A D F_{t}\right)$. While the $D F_{\rho}$ and $D F_{t}$ statistics assume strong exogeneity of regressors and errors and their parameters depend on nuisance parameters, the $D F_{\rho}^{*}$ and $D F_{t}^{*}$ statistics take into account the possible endogeneity between regressors and errors (see Appendix C.1). By construction, $D F_{\rho}^{*}, D F_{t}^{*}$ and $A D F_{t}^{9}$ do not depend on nuisance parameters and follow, according to a sequential asymptotic theory, ${ }^{10}$ a standard normal distribution. In what follows, we only refer to the last three statistics and we prefer to use the ADF statistic, because the associated unitroot regression can be proved to be a constrained version of the regression implemented to estimate the ARDL equation (see Appendix C.2).

Now, we turn to the "bounds tests" procedure.

\section{2 "Bounds tests" along the lines of Pesaran et al. (2001)}

For individual time series, starting from the VECM (equation (3)), Pesaran et al. (2001) test the error-correction and long-term coefficients, i.e. the following null hypothesis:

$$
H_{0}:\left\{\pi_{y y}=\pi_{y x . x}=0\right\},
$$

against the alternative $H_{1}:\left\{\pi_{y y} \neq 0\right.$ or $\left.\pi_{y x . x} \neq 0\right\}$.

The test statistic has a Fisher distribution, which depends on the integration order of series $Y$ and $X$ and also on the deterministic part of the long run equation. For example, at a significance level of $5 \%$, with no deterministic component, the critical value is equal to 5.73 if both series are $I(1)$ and 4.94 if they are both $I(0) .{ }^{11}$

When the statistic is smaller than a lower bound, the null hypothesis is not rejected, while it is rejected when the statistic is greater than an upper bound (5.73 for example, in

\footnotetext{
${ }^{8} M_{\{Z\}}=\left[I_{N} \otimes\left(I_{T}-\frac{e_{T} e_{T}^{\prime}}{T}\right)\right]$ which equivalent to "Within" operator $W_{N}$; where $I$ is identity matrix, $e_{T}^{\prime}=(111 \ldots 1)$ and $\mathcal{Z}=Z_{t}^{\prime} \gamma_{i}$.

${ }^{9} A D F_{t}$ statistic used to take into account both endogeneity of regressors and serial correlations of residuals.

${ }^{10} T \rightarrow \infty$ followed by $N \rightarrow \infty$.

${ }^{11}$ See tables in Pesaran et al. (2001), for more than one regressor.
} 
the case of two I(1) series). One cannot conclude between the two bounds. The previous test allows us to test for the existence of a relationship between the levels of the different series, whatever the stationarity properties of the regressors $(T S$ or $D S)$. It consists in testing whether the Long run parameters of equation (3) are jointly equal to 0.

Under the null hypothesis, the asymptotic distribution of the Fisher statistic is not standard, whatever the integration order of the regressors $(I(0)$ or $I(1))$.

Pesaran et al. (2001) also test for the null hypothesis:

$$
H_{0}:\left\{\pi_{y y}=0\right\}
$$

against the alternative $H_{1}:\left\{\pi_{y y} \neq 0\right\}$.

In what follows, we refer to the tables for the distribution of the $t_{\pi_{y y}}$ statistic, ${ }^{12}$ presented by Pesaran et al. (2001). Note however that in the panel context, Pesaran et al. (1999) conclude that $\pi_{y y}$ is significant by comparing its estimate to the corresponding standard error and observing that it is "highly significant" without referring to any table.

In order to test for cointegration, one needs to implement a sequential procedure. At the first step, one tests for the joint nullity of $\pi_{y y}$ and $\pi_{y x . x}$. If the null hypothesis is not rejected, one can be sure that $Y$ and $X$ do not cointegrate according to $\Delta Y$-equation. If the null is rejected, one has to look at $\pi_{y y}$ and $\pi_{y x . x}$ successively and test whether they are significant. At the second step, one implements the previous test for $\pi_{y y}=0$. If nullity of $\pi_{y y}$ is not rejected, one has to exclude any long run relationship including $Y$. If nullity of $\pi_{y y}$ is rejected, one should also test, in a third step, for the presence of $\mathrm{X}$ in the cointegration relation, i.e. one has to explicitly test for $H_{0}:\left\{\pi_{y x . x}=0\right\}$.

Unfortunately, this is not available in Pesaran et al's (2001) approach and would require an extension of their testing strategy. However, if one knows a priori that $Y$ is $I(1)$, then one can conclude that $Y$ and $X$ cointegrate and that $\pi_{y x . x} \neq 0$, once $\pi_{y y} \neq 0$. Indeed, the joint conditions $\pi_{y x . x}=0$ and $\pi_{y y} \neq 0$ would imply that $Y$ is $I(0)$ like the right member of the ARDL single equation rewritten as:

$$
-\left(\pi_{y y} Y_{t-1}+\pi_{y x . x} X_{t-1}\right)=c_{0}+c_{1} t+\Delta Y_{t}+\sum_{i=0}^{p-1} \Psi_{i}^{\prime} \Delta Z_{t-i}+\omega^{\prime} \Delta X_{t}+u_{t} .
$$

The extension of the results obtained by Pesaran et al. (2001) is beyond the topic of the present paper, and we only consider the first two steps.

\section{Empirical results}

We consider that credit demand depends on long run interest rates, as well as two scale variables, namely household investment and house prices. Credit is expressed in real terms:

$$
\ln \left(D_{i t} / P_{i t}\right)=\alpha_{i}+\beta_{i} t+\gamma_{i} \ln \left(I N V_{i t}\right)+\tau_{i} L T R_{i t}+\zeta_{i} \ln \left(P L O G_{i t}\right)+e_{i t}
$$

\footnotetext{
${ }^{12}$ In principle, one should also have verified before that $\Delta Y$ does not cause $\Delta X$ in Granger's sense. We assume that it is the case in our empirical study.
} 
where $D_{i t}$ is the stock of credit to households in country $i$ at date $t, I N V_{i t}$ is the investment variable, $L T R_{i t}$ is the long-term nominal interest rate, $\beta_{i}$ could measure the financial development trend, i.e. the tendency of financial assets/liabilities to grow more rapidly than GDP or income. ${ }^{13}$ Note that $\tau<0$ is consistent with a demand equation and $\gamma_{i}$ is expected to be positive and close to 1 . The empirical results are not satisfactory for specifications including the short run interest rate, which is not the usual reference for pricing loans to households. Indeed, housing loans represent usually more than $80 \%$ of total credit to households. PLOG is the real house price (i.e. divided by the consumption deflator).

The objective of the empirical strategy is to estimate such an equation including the long run equilibrium and the short run dynamics. Directly estimating the previous equation independently across countries (see "regression 1" below) often leads to the rejection of cointegration, due to the lack of power of usual tests. Taking advantage of the panel dimension we first test for cointegration, then implement the Pesaran et al.'s (1999) PMG approach.

To summarize, the different models that we estimate are the following :

Regression 1: Unrestricted country-by-country equation (whose average of coefficients yields the Mean Group or "MG" estimator), where $Y_{i t}$ stands for real credit, i.e. $\ln \left(D_{i t} / P_{i t}\right)$, and $X_{i t}$ for the different explanatory variables:

$$
\Delta Y_{i t}=\phi_{i}\left(Y_{i t-1}-\theta_{i}^{\prime} X_{i t}\right)+\sum_{j=1}^{p-1} \lambda_{i j}^{*} \Delta Y_{i t-j}+\sum_{j=0}^{q-1} \delta_{i j}^{* \prime} \Delta X_{i t-j}+\mu_{i}+\varepsilon_{i t}
$$

$\forall 1 \leq i \leq N$ and $1 \leq t \leq T$.

Regression 2: ARDL-ECM with common long run and free short run coefficients, namely the Pooled Mean Group or "PMG" estimator:

$$
\Delta Y_{i t}=\phi_{i}\left(Y_{i t-1}-\theta^{\prime} X_{i t}\right)+\sum_{j=1}^{p-1} \lambda_{i j}^{*} \Delta Y_{i t-j}+\sum_{j=0}^{q-1} \delta_{i j}^{* \prime} \Delta X_{i t-j}+\mu_{i}+\varepsilon_{i t}
$$

$\forall 1 \leq i \leq N$ and $1 \leq t \leq T$.

Regression 3 : Dynamic fixed effects (DFE), which assumes short and long run homogeneity (except the constant term):

$$
\Delta Y_{i t}=\phi\left(Y_{i t-1}-\theta^{\prime} X_{i t}\right)+\sum_{j=1}^{p-1} \lambda_{j}^{*} \Delta Y_{i t-j}+\sum_{j=0}^{q-1} \delta_{j}^{* \prime} \Delta X_{i t-j}+\mu_{i}+\varepsilon_{i t}
$$

$\forall 1 \leq i \leq N$ and $1 \leq t \leq T$.

Regression 2 is the model that we estimate, using the Schwarz criterion to validate the common lag structure. Starting from the unconstrained regression 1, we use a Hausman test to assess whether the homogeneity constraints can be accepted.

\footnotetext{
${ }^{13}$ None of the empirical results includes a deterministic trend, as it turns out not to be significant over the sample period.
} 


\subsection{Results from $\mathrm{ARDL}^{14}$}

We consider the model with households' investment, as well as the house price index in the long run relation as well as in the short run dynamics.

We first proceed with the Pooled Mean Group (PMG) approach for all countries. Table 1 provides the long run coefficients for the three regressions. In the PMG model, i.e. when constraining the nine countries to have the same long run relationship on the level of the variables as in regression 2, the long run coefficients have the right sign. The long run elasticity of credit to investment is around 1.6 and the elasticity of house prices is 0.57 , while the semi-elasticity of long-term interest rates is -0.1 . The Hausman test for overall homogeneity is not rejected indicating that PMG regression is supported by the data, in the sense that regression 2 is not statistically different from the average of the long run coefficients from regression 1 , exhibited in column.

Table 1: Panel estimates (9 countries)

model with investment, long-term nominal interest rates and house prices

\begin{tabular}{rccccccc}
\hline \hline lag $1 / 1 / 0 / 1$ & \multicolumn{2}{c}{ PMGE } & \multicolumn{2}{c}{ MGE } & \multicolumn{2}{c}{ DFE } & H-test $^{(1)}$ \\
& coef & t-ratio & coef & t-ratio & coef & t-ratio & p-value \\
\hline $\ln (I N V)$ & 1.578 & 7.279 & 1.329 & 1.128 & 2.642 & 2.124 & 0.83 (indiv.) \\
$L T R$ & -0.098 & -10.923 & -0.053 & -0.828 & -0.158 & -1.942 & 0.47 (indiv.) \\
$\ln (P L O G)$ & 0.570 & 6.611 & 0.846 & 1.193 & 0.151 & 0.356 & 0.70 (indiv.) \\
$\phi$ & -0.030 & -4.779 & -0.037 & -1.965 & -0.016 & -1.621 & 0.74 (joint) \\
\hline
\end{tabular}

${ }^{(1)}$ Hausman test comparing PMGE and MG results

PMGE : Pooled Mean Group Est.; MGE : Mean Group Est.; DFE : Dynamic Fixed Effect

However, when looking at the error-correction coefficient $\phi_{i}$ in the different countries (Table 2), it appears that it is not significant for two countries, namely Austria and Belgium. For the other countries, the equations exhibit good properties, in particular there is no autocorrelation of residuals. In the case of Italy, it is accepted but at the $1 \%$ level.

It is worth noting that assumption $\left(a_{1}\right)$ of Pesaran et al.'s (1999) PMG estimator is satisfied since we verify that there is no correlation of the residuals across countries according to a Pearson's test (see Appendix A.4 for results). ${ }^{15}$

Regarding the speed of adjustment as provided by the error-correction adjustment $\phi_{i}$, lower adjustement is observed in Italy and Ireland, while higher adjustment appears in the Netherlands and Germany.

\footnotetext{
${ }^{14}$ The results are based on the Gauss routine from Pesaran et al. (1999).

${ }^{15}$ The statistic of the Pearson test of significance of the correlation coefficient $r$ is $\frac{r \sqrt{n-2}}{\sqrt{1-r^{2}}}$ follows a Student distribution with $(n-2)$ degrees of freedom, where $n$ is the number of observations.
} 
Table 2: ECM coefficients in PMGE (9 countries) model with investment, long-term nominal interest rates and house prices

\begin{tabular}{rccccc}
\hline \hline country & $\phi_{i}$ & std-error & t-ratio & Resid autocorr. test $(\dagger)$ & $\bar{R}^{2}$ \\
\hline Austria & 0.003 & 0.006 & 0.460 & 0.02 & -0.06 \\
Belgium & $-0.010^{(* *)}$ & 0.008 & -1.272 & 4.17 & -0.08 \\
Germany & $-0.048^{(* *)}$ & 0.006 & -7.644 & 1.20 & 0.76 \\
Spain & $-0.030^{(* *)}$ & 0.007 & -4.474 & 0.02 & 0.59 \\
Finland & $-0.038^{(* *)}$ & 0.005 & -7.166 & 1.13 & 0.56 \\
France & $-0.038^{(* * *)}$ & 0.005 & -7.470 & 0.53 & 0.70 \\
Ireland & $-0.025^{(* *)}$ & 0.005 & -4.790 & 0.61 & 0.51 \\
Italy & $-0.026^{(* *)}$ & 0.008 & -3.222 & 5.84 & 0.25 \\
Netherlands & $-0.061^{(* *)}$ & 0.015 & -4.178 & 0.87 & 0.25 \\
\hline
\end{tabular}

PMGE : Pooled Mean Group Estimate; $(\dagger)$ Godfrey's test distributed as $\chi^{2}(1)$.

${ }^{(* * *)}$ Significance at $1 \%$ according to Student distribution.

The heterogeneity of short run dynamics also appears from comparing the estimates of the long run elasticities obtained for the Dynamic Fixed effects specification (DFE, 3rd column in Table 1) and the ones obtained with the PMG specification. As the introduction of different constraints on the short run dynamics (compare regr.2 and regr.3) does seem to matter, it implies that the short run dynamics are not identical across all countries. So we decide to drop Austria and Belgium and again use the PMG approach for seven countries. The results are almost unchanged for the PMG estimation (see Table 3), but the DFE estimation is now very close to the PMG. ${ }^{16}$

Table 3: Panel estimates ( 7 countries) model with investment, long-term nominal interest rates and house prices

\begin{tabular}{rccccccc}
\hline \hline $\operatorname{lag} 1 / 1 / 0 / 1$ & \multicolumn{2}{c}{ PMG } & \multicolumn{2}{c}{ MG } & \multicolumn{2}{c}{ DFE } & H-test $^{(1)}$ \\
& coef & t-ratio & coef & t-ratio & coef & t-ratio & p-value \\
\hline $\ln (I N V)$ & 1.593 & 7.257 & 1.834 & 1.246 & 1.517 & 6.885 & 0.87 (indiv.) \\
$L T R$ & -0.098 & -10.848 & -0.042 & -0.524 & -0.100 & -5.663 & 0.49 (indiv.) \\
$\ln (P L O G)$ & 0.565 & 6.508 & 0.895 & 0.965 & 0.533 & 4.058 & 0.72 (indiv.) \\
$\phi$ & -0.038 & -7.809 & -0.033 & -2.171 & -0.033 & -5.392 & 0.24 (joint) \\
\hline
\end{tabular}

${ }^{(1)}$ Hausman test comparing PMGE and MG results

PMGE : Pooled Mean Group Est.; MGE : Mean Group Est.; DFE : Dynamic Fixed Effect

Furthermore, the results appear stable over time on the basis of recursive CUSUM tests applied to the constrained PMG model with common long run relationship, or the unconstrained model, ${ }^{17}$ which we discuss more fully in the following section. The stability over time of country models exhibiting different short run dynamics leads to the conclusion

\footnotetext{
${ }^{16}$ Indeed, the DFE estimation is also supported by the data on the basis of a Hausman test, comparing MG and DFE, but we rely in the rest of the paper on the PMG model which is the most general specification. In addition, the existence of differences in the adjustment coefficient also favours the PMG model.

${ }^{17}$ Results for CUSUM tests are available upon request from the authors.
} 
that countries share common long run dynamics (as verified by the PMG specification), while institutional idiosyncrasies are still at play and persistent in the short run.

Such a conclusion, regarding the relatively good fit of the PMG model, is also apparent from simulating the models. The charts below exhibit the static as well as the dynamic simulation. In the first case, the model of regression 2 uses historical values for the lagged value of the endogenous variable, while in the latter case the estimated value is used recursively. The dynamic simulation is obviously a more stringent test of the model fit. It turns out that the dynamic simulation quite closely follows the actual year-on-year growth of real credit to households. This is more significantly so in the case of Germany and France, as well as Spain and the Netherlands. On the other hand, large discrepancies appear notably for Italy, but also for Finland and Ireland.
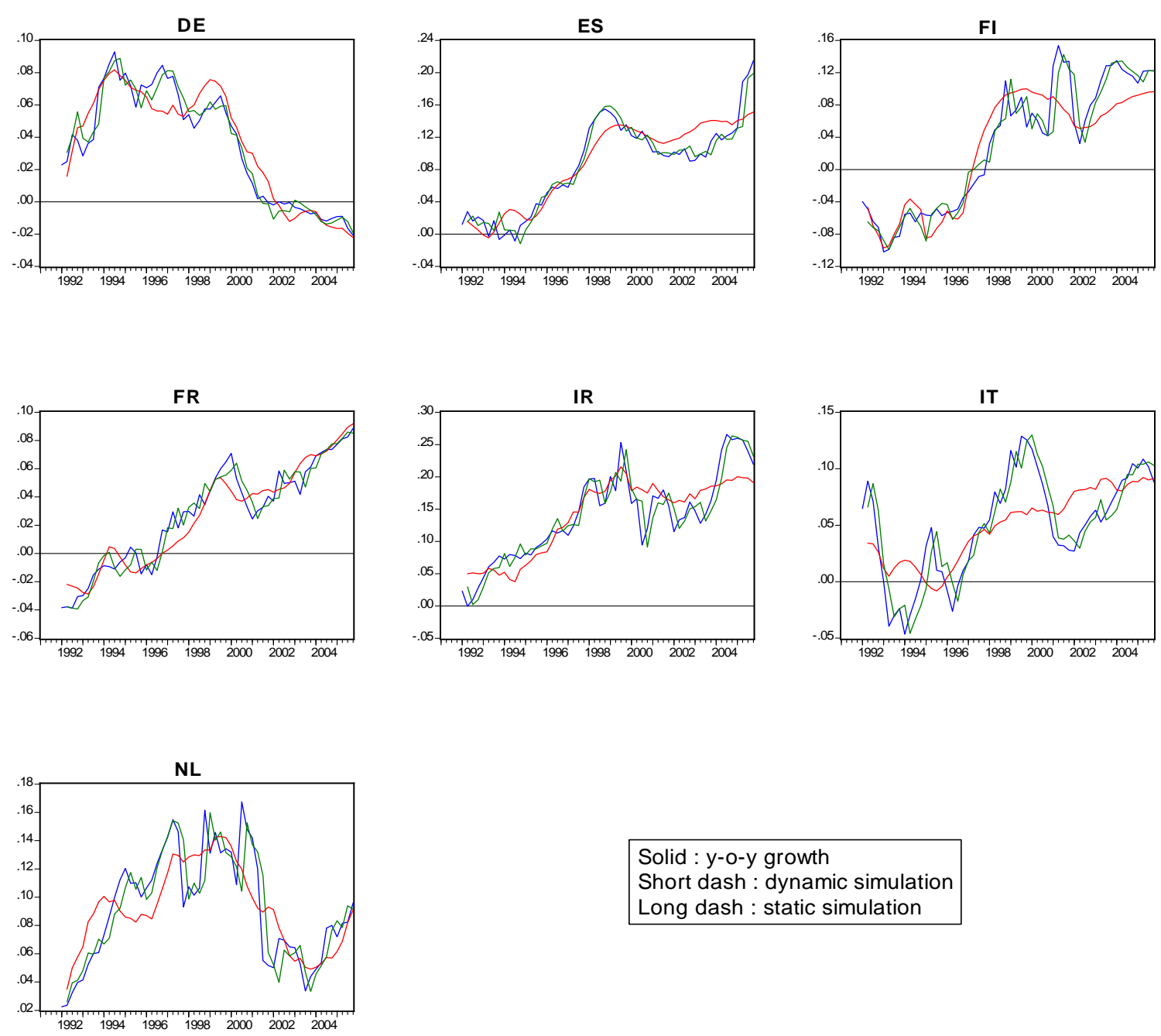

Figure 1 : Static and dynamic simulation of y-o-y real credit growth 
The conclusion at this stage is that credit behaviour exhibits similar long run behaviour across a significant number of countries in the euro area (France, Germany, Spain and to a lesser extent in Italy), while Ireland and Finland also share some common features, and the other countries (Austria and Belgium) still follow specific dynamics. This provides evidence of converging financial behaviour, even if short run dynamics, linked to institutions, are still different.

\section{Robustness Analysis}

We now consider two types of robustness analysis. First, we investigate whether there is indeed cointegration and whether we have identified a demand equation.

\subsection{Cointegration Analysis}

As indicated before, Pesaran's PMG model rests on the assumption that the variables are cointegrated and we proceed now to verify that assumption. Anticipating on the results of the subsection, we show that looking at various methods, either based on the panel structure of the data, or on the time series dimension, it appears that cointegration is only accepted for five to six countries out of seven, Italy exhibits different behaviour from the other countries.

\subsubsection{Kao's panel approach ${ }^{18}$}

On the basis of Kao's approach, it appears that cointegration is rejected for our set of nine countries and also on the set of seven countries. To get evidence of cointegration, if one refers to the $A D F$ statistic, which is the statistic we prefer for the reasons explained before, one needs to reduce the sample to six countries ( $\mathrm{p}$-value for $A D F_{t}$ is $10.6 \%$ ) or to five countries (p-value for $A D F_{t}$ is $0,09 \%$ ). In the following table, we report the values of the results obtained with the different test statistics for different sets of countries.

Table 4: Kao (1999) cointegration test

(Model with investment, long term nominal interest rates and house prices)

\begin{tabular}{clcccccc}
\hline \hline Stat. of tests & & \multicolumn{2}{c}{$D F_{\rho}^{*}$} & \multicolumn{2}{c}{$D F_{t}^{*}$} & \multicolumn{2}{c}{$A D F_{t}$} \\
\hline Subgroup & \multicolumn{1}{c}{ Countries } & t-stat & p-val & t-stat & p-val & t-stat & p-val \\
\hline 7 countries & DE,ES,FI,FR,IR,IT,NL & -0.254 & 0.399 & 0.222 & 0.588 & -0.771 & 0.220 \\
6 countries & DE,ES,FI,FR,IT,NL & -0.853 & 0.196 & -0.266 & 0.395 & -1.246 & 0.106 \\
5 countries & DE,ES,FR,IT,NL & -1.217 & 0.112 & -0.312 & 0.377 & -1.334 & 0.091 \\
4 countries & DE,ES,FR,NL & -2.649 & 0.004 & -0.892 & 0.186 & -1.862 & 0.031 \\
4 countries & DE,ES,IT,NL & -1.809 & 0.035 & -0.717 & 0.237 & -1.519 & 0.064 \\
3 countries & DE,ES,NL & -4.016 & 0.000 & -1.504 & 0.066 & -2.213 & 0.013 \\
\hline \hline
\end{tabular}

${ }^{18}$ The results are based on Kao's modified NPT (CNPT) routine by J. Hlouskova and M. Wagner. 


\subsubsection{Time series approach to cointegration}

Further evidence in favour of cointegration on a limited set of countries can be found from country-by-country analysis, either testing the significance of the error-correction mechanism or using the more restrictive "bounds tests".

Unconstrained models We first study the traditional approach of cointegration, ${ }^{19}$ examining the significance of the ECM coefficient in the individual time series. We therefore study the properties of unconstrained models, where the long run relationship is countryspecific, according to the traditional time series approach. It turns out that Finland and Ireland no longer have a significant adjustment mechanism (see Table 5).

More generally, one concludes that the intensity of error-correction mechanism - measured by the $\phi_{i}$ coefficient - varies with the country. This result is in favor of short-term heterogeneity.

Table 5: ECM coefficients country-by-country (unconstrained) Model with investment, long-term nominal interest rates and house prices

\begin{tabular}{|c|c|c|c|c|c|c|}
\hline Country & $\phi_{i}$ & std-err. & Lag struc. & inf. crit. $^{(2)}$ & Autocorr. $(\dagger)$ & $\overline{\bar{R}^{2}}$ \\
\hline $\mathrm{DE}$ & $-0.058^{(* * *)}$ & 0.011 & $1 / 1 / 0 / 2$ & $S B C$ & 0.13 & 0.80 \\
\hline ES & $-0.111^{(* * *)}$ & 0.034 & $3 / 3 / 2 / 3$ & $A I C$ & 0.03 & 0.79 \\
\hline FI & -0.015 & -0.016 & $3 / 1 / 0 / 0$ & $A I C$ & 0.01 & 0.64 \\
\hline $\mathrm{FR}^{(1)}$ & $-0.541^{(* *)}$ & 0.119 & $1 / 3 / 3 / 2$ & $S B C$ & 5.92 & 0.82 \\
\hline IR & 0.012 & 0.024 & $1 / 1 / 0 / 1$ & $A I C / H Q$ & 0.00 & 0.54 \\
\hline $\mathrm{IT}$ & $-0.099^{(* * *)}$ & 0.041 & $1 / 0 / 3 / 1$ & $A I C / H Q / S B C$ & 0.10 & 0.47 \\
\hline $\mathrm{NL}^{(1)}$ & $-0.212^{(* * *)}$ & 0.059 & $1 / 2 / 0 / 0$ & $S B C$ & 0.97 & 0.34 \\
\hline \multicolumn{7}{|c|}{${ }^{(1)}$ Models with unrestricted intercept and unrestricted trend } \\
\hline \multicolumn{7}{|c|}{${ }^{(2)} A I C, S B C$ and $H Q$ are resp. Akaike, Schwarz Bayesian and Hannan-Quinn infomation criteria } \\
\hline \multicolumn{7}{|c|}{ Sign.level : ${ }^{(* * *)} 1 \%,{ }^{(* *)} 5 \%$ and ${ }^{(*)} 1 \% ;(\dagger)$ Godfrey's test as $\chi^{2}(1):$ autocorr. rejected at $5 \%$, but $1 \%$ for France } \\
\hline
\end{tabular}

"Bounds tests" Using the "bounds tests" advocated by Pesaran et al. (2001), we validate the joint significance of the long run and the adjustment coefficients (column 1 of Table 6, based on a Fisher test). However, it appears to be more difficult to validate the significance of the $\phi_{i}$ coefficient only (column 2 in Table 6), since our t-statistics are below the high critical value suggested by Pesaran et al. (2001). The null hypothesis of non-cointegration is only rejected for Germany and France, while inconclusive results are found for Spain and the Netherlands.

It should be kept in mind that this test is run on individual time series and does not take advantage of the panel nature of our database, since the critical values are not

\footnotetext{
${ }^{19}$ For illustration purposes, we present results implementing Banerjee et al.'s (1998) approach, with a simple test of significance (Student $\mathrm{t}$ ) of the error-correction mechanism $\phi_{i}$ from an OLS estimation of the ECM model.
} 
available in the panel context. One may think that our series are too short to display cointegration properties.

Indeed, Hofmann (2001) who uses time series similar to ours but over a longer period (1980-1998) validates cointegration for 16 OECD countries and his estimates of the long run coefficients are quite close to our estimates (with average values of the output, interest rate and property price coefficients about $1.3,-0.02$ and 0.60 respectively).

Table 6 : Bounds Testing on unconstrained models

\begin{tabular}{|c|c|c|}
\hline Tests & $\begin{array}{l}H_{0}^{\pi_{y y}}: \pi_{y y}=0, H_{0}^{\pi_{y x . x}}: \pi_{y x \cdot x}=0^{\prime} \\
H_{1}^{\pi_{y y}}: \pi_{y y} \neq 0, H_{1}^{\pi_{y x . x}}: \pi_{y x . x} \neq 0^{\prime}\end{array}$ & $\begin{array}{l}H_{0}^{\pi_{y y}}: \pi_{y y}=0 \\
H_{1}^{\pi_{y y}}: \pi_{y y} \neq 0\end{array}$ \\
\hline Country & F-statistic & t-statistic \\
\hline$\overline{\mathrm{DE}}$ & $30.84^{(* * *)}$ & $-5.51^{(* *)}$ \\
\hline $\mathrm{ES}$ & $4.40^{(* *)}$ & -3.23 (inconclusive inference) \\
\hline FI & $8.2^{(* * *)}$ & -0.93 \\
\hline $\mathrm{FR}^{(1)}$ & $7.92^{(* * *)}$ & $-4.52^{(* *)}$ \\
\hline IR & $8.48^{(* * *)}$ & 0.48 \\
\hline IT & $6.97^{(* * *)}$ & -2.42 \\
\hline $\mathrm{NL}^{(1)}$ & $6.99^{(* * *)}$ & -3.60 (inconclusive inference) \\
\hline \multicolumn{3}{|c|}{ 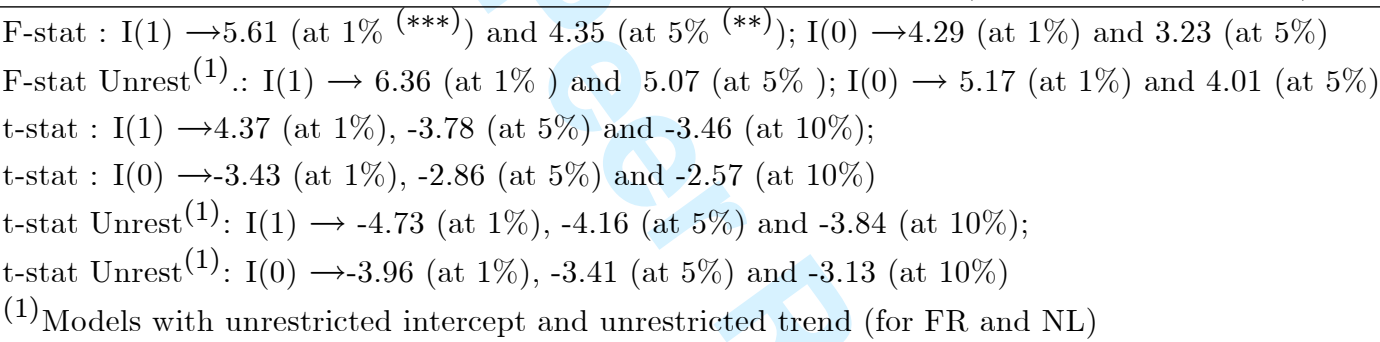 } \\
\hline
\end{tabular}

So, the results we obtain with the "bounds tests" do not really challenge the ones based on the Kao test and presented in section 6.1.1.

Even if cointegration is not accepted for all the countries in the panel, the long run coefficients are quite stable over the sample of countries. As indicated in the table in Appendix A.2, and as compared with Table 3, the long run coefficients are relatively unaffected for the different subsamples of countries we consider. It also implies, nevertheless, that the dynamic simulations for the four "core" countries, namely Germany, France, Spain and the Netherlands are not significantly improved when the PMG long run relationship is computed on this smaller set of countries (see Appendix A.3). ${ }^{20}$

\subsection{Analysis of Supply vs Demand shocks}

As a further robustness check of our previous approach, we now consider whether we have truly identified a demand equation.

\footnotetext{
${ }^{20}$ In addition, the absence of cointegration for panel data has different implications than in the pure time series context, since the estimator remains consistent in the former case, while it creates spurious results in the latter case (Entorf, 1997; Kao, 1999).
} 
Table 7: Correlation of residuals with changes in bank profits model with investment, long-term nominal interest rates and house prices

\begin{tabular}{rcccc}
\hline \hline country & gross inc./assets & net inc./assets & prof. bef. tax/assets & gross inc./loans \\
\hline Germany & -0.07 & 0.07 & 0.17 & -0.08 \\
Spain & -0.08 & 0.00 & 0.09 & -0.19 \\
Finland & 0.26 & 0.04 & 0.07 & 0.27 \\
France & -0.16 & -0.28 & 0.27 & -0.37 \\
Ireland & 0.05 & -0.18 & 0.10 & $-0.70(* * *)$ \\
Italy & 0.15 & 0.13 & 0.39 & -0.25 \\
Netherlands & -0.35 & -0.19 & -0.17 & 0.65 \\
\hline$(* * *)$ & Signif. diff. from zero at $1 \% \mathrm{w} /$ Pearson test stat. $\frac{r \sqrt{n-2}}{\sqrt{1-r^{2}}}$, distributed as Student t \\
\hline \hline
\end{tabular}

We study whether the equation we estimated identifies credit demand, as opposed to credit supply behaviour. We test whether the residuals of the equation are correlated with indicators measuring credit supply behaviour and in particular bank profitability. For that purpose, we use data collected by OECD (2005). We compute several indicators of profitability: (1) gross interest income/total assets, (2) net interest income/total assets, (3) profit before tax/total assets and (4) gross interest income/total loans. The first three indicators are overall indicators of profitability, while the latter measures the interest margin on loans.

Data from OECD are only available at an annual frequency for the period 1991-2004 and we average the dynamic residuals from the PMG equation (i.e. the $\varepsilon_{i t}$ 's in regression 2 ). It turns out that for almost all indicators the correlation is not significantly different for zero (Table 7).

The only exception is Ireland for indicator (4). Indeed, the PMG model appears to be unsatisfactory for Ireland. We conclude therefore that, except for Ireland, we mainly capture credit demand behaviour for most countries.

\section{Conclusion}

In the paper, we focus on the credit demand behavior of households in the euro area countries. In particular, we examine whether a common behavior can be captured through a unique long run equation, with transitory specific features in the short run dynamics. So, we look for long-term relationships within the framework of an ARDL model which allows testing for homogeneity of the long run (and the short run) dynamics. We validate the existence of a long run equation between credit volume, investment, long run nominal interest rate and an additional "fundamental", namely a relative house-price index and we interpret this equation as a demand equation, as the estimated corresponding residuals are found not to be correlated with supply factors like bank profitability. This long run equation can be constrained to be homogeneous for seven European countries and cointegration is validated for the five larger countries. In addition, short run homogeneity is rejected, indicating that countries have only partially converged in terms of financial structures. 
The question of why there is greater convergence between the larger countries is reserved for future work. One can mention, however, at this stage that the smaller countries whose banking systems are more open to the rest of the world, hence more subject to external shocks (including cross country M\&As, etc.), are more likely to experience possible regime shifts.

\section{References}

[1] Banerjee, A., J. J. Dolado, J. W. Galbraith and D. F. Hendry (1993), Co-Integration, Error-Correction and the Econometric Analysis of Non-stationary Data, Oxford University Press, Oxford.

[2] Banerjee, A., J. J. Dolado and R. Mestre (1998), "Error-correction mechanism tests for cointegration in a single-equation framework," Journal of Time Series Analysis , 19, 269-283.

[3] Bardsen, G. (1989), "Estimation of Long Run coefficients in Error-correction Models," Oxford Bulletin of Economics and Statistics, 51(3), 345-450.

[4] Bernanke, B. (1988), "Monetary policy transmission: through money or credit?," Business Review, Federal Reserve Bank of Philadelphia, 11, 3-11.

[5] Bewley, R. (1979), "The Direct Estimation of the Equilibrium Response in a Linear Dynamic Model," Economics Letters, 3, 357-361

[6] Calza, A., C. Gartner and J. Sousa (2003), "Modelling the Demand for Loans to the Private Sector in the Euro Area," Applied Economics, 35(1), 107-117.

[7] De Greef, J. J. M. and R. T. A. de Haas (2000), "Housing Prices, Bank Lending and Monetary Policy," Research Series Supervision No 31, De Nederlandsche Bank.

[8] European Central Bank (2002), Report on Financial structures, ECB, Frankfurt am Main.

[9] Entorf, H. (1997), "Random walks with drifts: Nonsense regression and spurious fixed-effect estimation," Journal of Econometrics, 80, 287-296.

[10] Fase, M. M. G. (1995), "The Demand for Commercial Bank Loans and the Lending Rate", European Economic Review, 39(1), 99-115.

[11] Fisher, I. (1933), "The debt-deflation theory of great depressions," Econometrica, 1, 337-357.

[12] Friedman B. M. and K. N. Kuttner (1993), "Another look at the evidence on moneyincome causality," Journal of Econometrics, 57(1-3),189-203. 
[13] Gimeno, R. and C. Martinez-Carrascal (2006), "The Interaction Between House Prices and Loans for House Purchase: the Spansih Case," Banco de Espana, Working Paper 0605 .

[14] Gouteron, S. and D. Szpiro (2005), "Excess liquidity and asset prices," Banque de France, Notes d'Etudes et de Recherche, \# 131.

[15] Hendry, D. F., A. R. Pagan and J. D. Sargan (1984), "Dynamic specification". In Griliches, Z. and M. D. Intriligator (ed) Handbook of Econometrics, vol. 2-3, Chapter 18, Amsterdam, North Holland.

[16] Hofmann, B. (2001), "The determinants of private sector credit in industrialised countries : do property prices matter?," Bank for International Settlements, Working Paper \# 108.

[17] Iacoviello, M. (2005), "House Prices, Borrowing Constraints, and Monetary Policy in the Business Cycle", American Economic Review, 95(3), 739-764.

[18] Kao, C. D. (1999), "Spurious Regression and Residual-Based Tests for Cointegration in Panel-data," Journal of Econometrics, 90(1), 1-44.

[19] Kiyotaki, N. and J. Moore (1997), "Credit Cycles," Journal of Political Economy, $105(2), 211-48$.

[20] Neven, D., L. H. Röller (1999), "An aggregate Structural Model of Competition in the European Banking Industry," International Journal of Industrial Organization, 17(7), 1059-1074.

[21] Pesaran, M. H, Y. Shin and R. P. Smith (1999), "Pooled mean group estimation of dynamic heterogeneous panels," Journal of the American Statistical Association, 94, 621-634.

[22] Pesaran, M. H., Y. Shin and R. P. Smith (2001), "Bounds Testing Approaches to the Analysis of Level Relationships," Journal of Applied Econometrics, 16, 289-326.

[23] Pesaran, M. H., and Y. Shin (1999), "An Autoregressive Distributed Lag Modelling Approach to Cointegration Analysis" in "Econometrics and Economic Theory in the 20th Century", S. Strom (ed.), chapter 11, Cambridge University Press.

\section{Acknowledgements}

The authors thank Claudine Guibert for providing excellent research assistance in compiling the database, as well as seminar participants at the Banque de France, the Bank of England and Maatstricht University, in particular Jean-Pierre Urbain, for useful comments. 


\section{A Appendix}

\section{A.1 Data description}

Data for household credit demand come from Eurosystem Statistics for the Q1 1991-Q4 2005 period, backdated with national data available from BIS. The other macroeconomic indicators are from OECD Economic Outlook database. Data on house prices come from a variety of national prices on existing dwellings, except for Italy where the data cover new houses. In addition, in the case of Germany, annual figures have been interpolated to yield quarterly figures.

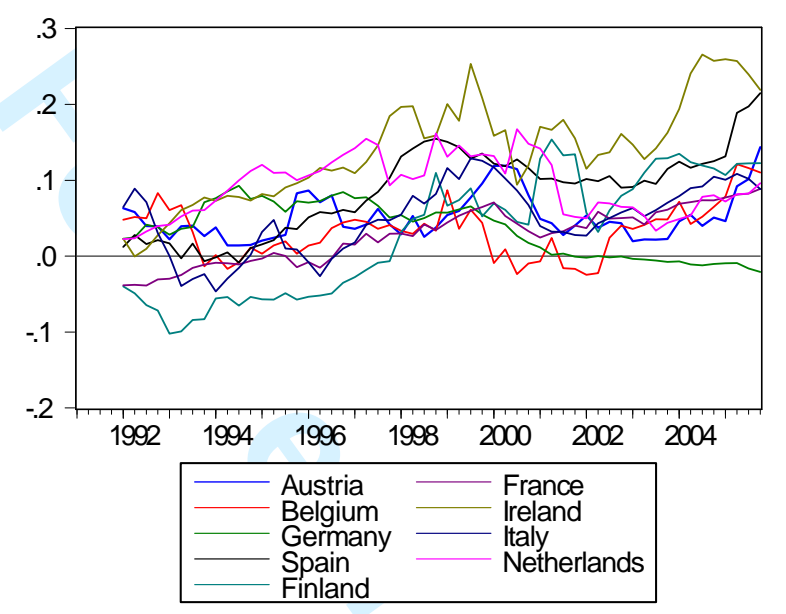

Figure 2: Household credit demand (y-o-y growth)

\section{A.2 Pooled Mean Group estimates on different samples of countries}

Table A: Estimation of cointegration relationship

Model with investment, long-term nominal interest rates and house prices

\begin{tabular}{llllllllll}
\hline \hline & \multicolumn{3}{c}{$\ln (I N V)$} & \multicolumn{3}{c}{$L T R$} & \multicolumn{3}{c}{$\ln ($ PLOG $)$} \\
\hline Subgroup & PMGE & MGE & DFE & PMGE & MGE & DFE & PMGE & MG & DFE \\
\hline 6 countries & 1.560 & 2.622 & 1.777 & -0.098 & -0.103 & -0.093 & 0.571 & 0.532 & 0.522 \\
DE,ES,FI,FR,IT,NL & $(7.150)$ & $(1.783)$ & $(5.636)$ & $(-10.894)$ & $(-1.631)$ & $(-6.032)$ & $(6.614)$ & $(0.527)$ & $(4.041)$ \\
5 countries & 1.533 & 3.077 & 1.507 & -0.095 & -0.043 & -0.087 & 0.549 & -0.262 & 0.546 \\
DE,ES,FR,IT,NL & $(7.033)$ & $(1.796)$ & $(6.447)$ & $(-10.480)$ & $(-1.755)$ & $-7.630)$ & $(6.314)$ & $(-0.342)$ & $(4.024)$ \\
4 countries & 1.355 & 1.295 & 1.554 & -0.089 & -0.072 & -0.081 & 0.653 & 0.672 & 0.564 \\
DE,ES,FR,NL & $(7.548)$ & $(11.673)$ & $(4.959)$ & $(-10.425)$ & $(-9.010)$ & $(-11.171)$ & $(8.779)$ & $(4.051)$ & $(4.248)$ \\
4 countries & 1.348 & 3.489 & 1.250 & -0.092 & -0.037 & -0.083 & 0.723 & -0.392 & 0.686 \\
DE,ES,IT,NL & $(6.400)$ & $(1.626)$ & $(18.853)$ & $(-9.825)$ & $(-1.210)$ & $(-11.198)$ & $(8.200)$ & $(-0.403)$ & $(8.873)$ \\
3 countries & 1.266 & 1.198 & 1.351 & -0.083 & -0.069 & -0.076 & 0.778 & 0.823 & 0.697 \\
DE,ES,NL & $(0.902)$ & $(15.820)$ & $(36.078)$ & $(-8.828)$ & $(-6.621)$ & $(-44.762)$ & $(10.443)$ & $(8.450)$ & $(7.936)$ \\
\hline \hline
\end{tabular}


A.3 Dynamic simulation of the PMG models (regression 2 in section 5) with long run equilibrium defined on 4 countries only
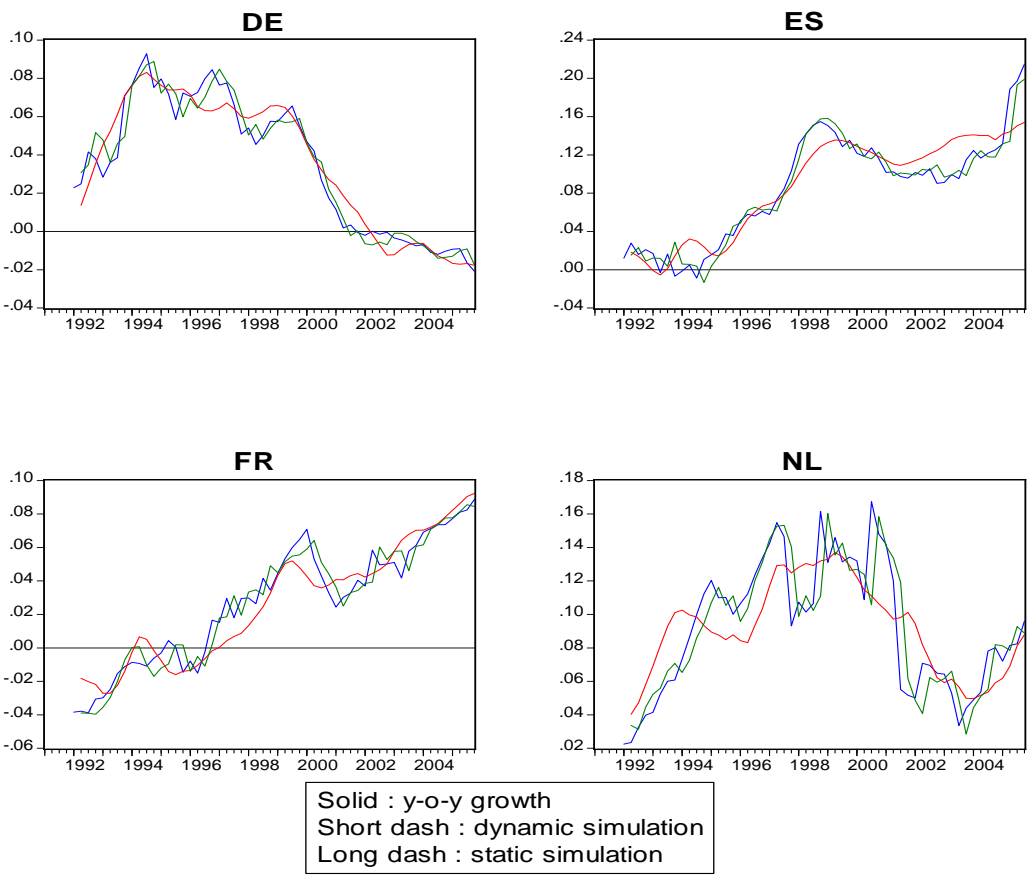

Figure 3: Dynamic simulation on the PMG model, when the long run is estimated on 4 countries

\section{A.4 Correlation between residuals in the dynamic equation (regression} 2 in section 5)

Table B : Cross-correlation of dynamic resid.

model with investment, long-term nominal interest rates and house prices

\begin{tabular}{cccccccc}
\hline \hline Country & DE & ES & FI & FR & IR & IT & NL \\
\hline DE & $\cdot$ & $-0.22^{(* *)}$ & $-0.03^{(* *)}$ & $0.03^{(* *)}$ & $0.13^{(* *)}$ & $0.16^{(* *)}$ & $-0.03^{(* *)}$ \\
ES &. &. & $-0.10^{(* *)}$ & $0.05^{(* *)}$ & $-0.09^{(* *)}$ & 0.26 & $0.16^{(* *)}$ \\
FI &. &. &. & $0.07^{(* *)}$ & $0.23^{(* *)}$ & $-0.15^{(* *)}$ & $0.10^{(* *)}$ \\
FR &. &. &. &. & $0.17^{(* *)}$ & $0.21^{(* *)}$ & $-0.01^{(* *)}$ \\
IR &. &. &. &. &. & $0.09^{(* *)}$ & $-0.24^{(* *)}$ \\
IT &. &. &. &. &. &. & $-0.02^{(* *)}$ \\
NL &. &. &. &. &. &. \\
\hline \multicolumn{7}{c}{ Pearson test of significance of the correlation coefficient $r$} \\
\hline \hline
\end{tabular}




\section{B The ARDL specification}

\section{B.1 VECM characterization of the dynamics:}

The VECM is written as:

$$
\left\{\begin{array}{c}
\Delta Y_{t}=c_{0}+c_{1} t+\pi_{y y} Y_{t-1}+\pi_{y x} X_{t-1}+\sum_{i=1}^{p-1} \Gamma_{y i} \Delta Z_{t-i}+\varepsilon_{y t} \\
\Delta X_{t}=a_{0}+a_{1} t+\pi_{x y} Y_{t-1}+\Pi_{x x} X_{t-1}+\sum_{i=1}^{p-1} \Gamma_{x i} \Delta Z_{t-i}+\varepsilon_{x t}
\end{array}\right.
$$

with $\Pi=\left[\begin{array}{ll}\pi_{y y} & \pi_{y x} \\ \pi_{x y} & \Pi_{x x}\end{array}\right]$. If one multiplies both members of the previous equation by the matrix:

$$
P=\left[\begin{array}{cc}
1 & -\omega_{y x} \Omega_{x x}^{-1} \\
0 & I d
\end{array}\right]
$$

Thus, the $\Delta Y$ and $\Delta X$ innovations are orthogonalized and one gets the equivalent characterization:

$$
\begin{gathered}
\left\{\begin{array}{l}
\Delta Y_{t}=c_{0}+c_{1} t+\pi_{y y} Y_{t-1}+\pi_{y x . x} X_{t-1}+\sum_{i=0}^{p-1} \Psi_{i}^{\prime} \Delta Z_{t-i}+\omega^{\prime} \Delta X_{t}+u_{t} \\
\Delta X_{t}=a_{0}+a_{1} t+\pi_{x y} Y_{t-1}+\Pi_{x x} X_{t-1}+\sum_{i=1}^{p-1} \Gamma_{x i} \Delta Z_{t-i}+\varepsilon_{x t}
\end{array}\right. \\
\Leftrightarrow\left\{\begin{array}{l}
\left(1-\left(1+\pi_{y y}\right) L\right) Y_{t}=c_{0}+c_{1} t+\pi_{y x . x} X_{t-1}+\sum_{i=0}^{p-1} \Psi_{i}^{\prime} \Delta Z_{t-i}+\omega^{\prime} \Delta X_{t}+u_{t} \\
\left(I d-\left(I d+\Pi_{x x}\right) L\right) X_{t}=a_{0}+a_{1} t+\pi_{x y} Y_{t-1}+\sum_{i=1}^{p-1} \Gamma_{x i} \Delta Z_{t-i}+\varepsilon_{x t}
\end{array}\right.
\end{gathered}
$$

$c_{0}=\alpha_{y 0}-\omega^{\prime} \alpha_{x 0}$ and $c_{1}=\alpha_{y 1}-\omega^{\prime} \alpha_{x 1}$ where $\omega=\Omega_{x x}^{-1} \omega_{x y} ; \alpha_{0}=\left(\alpha_{y 0}, \alpha_{x 0}^{\prime}\right)^{\prime} ; \alpha_{1}=$ $\left(\alpha_{y 1}, \alpha_{x 1}^{\prime}\right)^{\prime}$. And $u_{t}=\varepsilon_{y t}-\omega_{y x} \Omega_{x x}^{-1} \varepsilon_{x t}$ with $\omega_{u u}=\omega_{y y}-\omega_{y x} \Omega_{x x}^{-1} \omega_{x y}$; note that $u_{t}$ i.i.d. $N\left(0, \omega_{u u}\right)$.

The matrix of long run coefficients $\Pi$ has been partitioned according to:

$$
\Pi=\left(\pi_{y}^{\prime}, \Pi_{x}^{\prime}\right)^{\prime}=\alpha \beta^{\prime},
$$

where $\alpha=\left(\alpha_{y x}^{\prime}, \alpha_{x x}^{\prime}\right)^{\prime}$ and $\beta=\left(\beta_{y x}^{\prime}, \beta_{x x}^{\prime}\right)^{\prime}$. With $\pi_{y x . x}=\pi_{y x}-\omega^{\prime} \Pi_{x x}($ matrix $1 \times k)$ and $\pi_{y \cdot x}=\pi_{y}-\omega^{\prime} \Pi_{x}($ matrix $1 \times(k+1))$.

Matrix $\Pi_{x x}$ is supposed to have rank $r, 0 \leq r \leq k$ where $k$ is the dimension of $X^{21} \cdot r$ is the minimum rank of $\Pi$ and $r+1$ its maximum $\mathrm{rank}$ where $\Pi=\alpha \beta^{\prime 22}$. When $\Pi$ has rank $r$, one has $\pi_{y y}=0$ as one has supposed that $\pi_{x y}=0$ (see Pesaran et al. 2001) and thus:

$$
\Pi=\left[\begin{array}{cc}
0 & \pi_{y x} \\
0 & \Pi_{x x}
\end{array}\right]
$$

In this case $\beta_{y x}$ has to be null.

\footnotetext{
${ }^{21} \Pi_{x x}=\alpha_{x x} \beta_{x x}^{\prime}$ where $\alpha_{x x}$ and $\beta_{x x}$ are two matrices $k \times r$ of full column rank $r$.

${ }^{22} \alpha=\left(\alpha_{y x}^{\prime}, \alpha_{x x}^{\prime}\right)^{\prime}$ and $\beta=\left(\beta_{y x}^{\prime}, \beta_{x x}^{\prime}\right)^{\prime}$ are two $(k+1) \times(r+1)$ dimensional matrices while $\alpha_{y x}, \alpha_{x x}, \beta_{y x}, \beta_{x x}$ are respectively $1 \times(r+1), k \times(r+1), 1 \times(r+1)$ and $k \times(r+1)$.
} 


\section{B.2 Links between the parameters of the VECM and of the ones of the ARDL model}

1) One notes that the long run parameters of the ARDL model are different from the ones that one would derive from a standard VECM with no contemporaneous variables $\Delta X_{t}$ :

$$
\theta^{*}=-\pi_{y x} / \pi_{y y}
$$

2) It is worth emphasizing that one cannot estimate the usual parameters of a VECM just from the "single equation":

$$
\Delta Y_{t}=c_{0}+c_{1} t+\pi_{y y} Y_{t-1}+\pi_{y x . x} X_{t-1}+\sum_{i=1}^{p-1} \Psi_{i}^{\prime} \Delta Z_{t-i}+\omega^{\prime} \Delta X_{t}+u_{t} .
$$

Indeed, by regressing $\Delta Y_{t}$ onto constant, time, $Y_{t-1}, X_{t-1}, \Delta X_{t}$ and $\Delta Y_{t-i}, 1 \leq i \leq p-1$, one can estimate $\pi_{y y}, \pi_{y x . x}, \omega$, and $\Psi_{i}, 1 \leq i \leq p-1$. Accordingly, one can estimate the error-correcting intensity $\pi_{y y}$ associated with a long run relationship identified by imposing that $Y^{\prime}$ s coefficient is equal to 1 , but one cannot estimate parameters $\pi_{y x}=\pi_{y x . x}+\omega^{\prime} \Pi_{x x}$.

$\Pi_{x x}$ can only be estimated by jointly estimating the VECM equation of $X$ :

$$
\Delta X_{t}=a_{0}+a_{1} t+\pi_{x y} Y_{t-1}+\Pi_{x x} X_{t-1}+\sum_{i=1}^{p-1} \Gamma_{x i} \Delta Z_{t-i}+\varepsilon_{x t} .
$$

\section{Kao's (1999) tests}

\section{C.1 The different test statistics}

Let the bivariate process $w_{i t}^{\prime}=\left(\mu_{i t}, \vartheta_{i t}\right)^{\prime}$ for $i=1, \ldots, N$ and $t=1, \ldots, T$, with $Y_{i t}=\sum_{s=1}^{t} \mu_{i s}$ and $X_{i t}=\sum_{s=1}^{t} \vartheta_{i s}$. The long-term variance-covariance $\Omega$ of $w_{i t}$ (under the homogeneity assumption) is written as:

$$
\begin{aligned}
& \Omega=\lim _{T \rightarrow \infty} E\left[T^{-1}\left(\sum_{t=1}^{T} w_{i t}\right)\left(\sum_{t=1}^{T} w_{i t}\right)\right] \\
&=\lim _{T \rightarrow \infty} E\left[T^{-1} \sum_{t=1}^{T} w_{i t} w_{i t}^{\prime}\right]+\lim _{T \rightarrow \infty} E\left[T^{-1} \sum_{k=1}^{T-1} \sum_{t=k+1}^{T} w_{i t} w_{i t-k}^{\prime}\right]+\lim _{T \rightarrow \infty} E\left[T^{-1} \sum_{k=1}^{T-1} \sum_{t=k+1}^{T} w_{i t-k} w_{i t}^{\prime}\right] \\
&=\Sigma+\Gamma+\Gamma^{\prime} \\
& \text { with } \quad \Omega=\left[\begin{array}{cc}
\sigma_{0 \mu}^{2} & \sigma_{0 \mu \vartheta} \\
\sigma_{0 \vartheta \mu} & \sigma_{0 \vartheta}^{2}
\end{array}\right], \Sigma=\left[\begin{array}{cc}
\sigma_{\mu}^{2} & \sigma_{\mu \vartheta} \\
\sigma_{\vartheta \mu} & \sigma_{\vartheta}^{2}
\end{array}\right] \text { et } \Gamma=\left[\begin{array}{cc}
\Gamma_{\mu} & \Gamma_{\mu \vartheta} \\
\Gamma_{\vartheta \mu} & \Gamma_{\vartheta}
\end{array}\right]
\end{aligned}
$$

From equation (A), the OLS estimator of $\rho$ and its t-statistic are given by :

$$
\widehat{\rho}=\frac{\sum_{i=1}^{N} \sum_{t=2}^{T} \widehat{e}_{i t} \widehat{e}_{i t-1}}{\sum_{i=1}^{N} \sum_{t=2}^{T} \widehat{e}_{i t-1}^{2}} \text { et } t_{\rho}=(\widehat{\rho}-1) \sqrt{\frac{N T \sum_{i=1}^{N} \sum_{t=2}^{T} \widehat{e}_{i t-1}^{* 2}}{\sum_{i=1}^{N} \sum_{t=2}^{T}\left(\widehat{e}_{i t}^{*}-\widehat{\rho}_{i t-1}^{*}\right)^{2}}},
$$


The four Dickey-Fuller type statistics are defined as follows:

$$
\begin{gathered}
D F_{\rho}=\frac{\sqrt{N} T(\widehat{\rho}-1)+3 \sqrt{N}}{\sqrt{10.2}}, \quad D F_{\rho}^{*}=\frac{\sqrt{N} T(\widehat{\rho}-1)+\frac{3 \sqrt{N} \widehat{\sigma}_{v}^{2}}{\widehat{\sigma}_{0 v}^{2}}}{\sqrt{3+\frac{3 \sigma_{v}^{4}}{5 \widehat{\sigma} \hat{\sigma}_{0 v}^{2}}}} \\
D F_{t}=\sqrt{1.25} t_{\rho}+\sqrt{1.875} N, \quad D F_{t}^{*}=\frac{t_{\rho}+\frac{\sqrt{6 \widehat{\sigma}_{v}}}{2 \widehat{\sigma}_{0 v}^{2}}}{\sqrt{\frac{\widehat{\sigma}_{0 v}^{2}}{2 \widehat{\sigma}_{v}^{2}}+\frac{3 \widehat{\sigma}_{v}^{2}}{10 \widehat{\sigma}_{0 v}^{2}}}},
\end{gathered}
$$

with $\sigma_{0 v}^{2}=\sigma_{0 \mu}^{2}-\sigma_{0 \mu \vartheta}^{2} \sigma_{0 \vartheta}^{-2}$ and $\sigma_{v}^{2}=\sigma_{\mu}^{2}-\sigma_{\mu \vartheta}^{2} \sigma_{\vartheta}^{-2}\left(\widehat{\sigma}_{0 v}^{2}\right.$ and $\widehat{\sigma}_{v}^{2}$ are consistent estimators of $\sigma_{0 v}^{2}$ and $\sigma_{v}^{2}$ ). The statistic of the Augmented Dickey-Fuller type test based on regression in equation $(\mathrm{B})$ is:

$$
A D F=\frac{t_{A D F}+\frac{\sqrt{6 N} \widehat{\sigma}_{v}}{2 \widehat{\sigma}_{0 \mu}^{2}}}{\sqrt{\frac{\widehat{\sigma}_{0 v}^{2}}{2 \widehat{\sigma}_{v}^{2}}+\frac{3 \widehat{\sigma}_{v}^{2}}{10 \widehat{\sigma}_{0 v}^{2}}}},
$$

where $t_{A D F}$ is the t-statistic of $\rho$ in $(\mathrm{B})$.

Kao (1999) proves according to a sequential asymptotic theory, that the $D F_{\rho}^{*}, D F_{t}^{*}$ and $A D F_{t}$ statistics follow a $N(0,1)$ distribution. However, results from various Monte Carlo simulations cannot conclude the superiority of one statistic, since the results are very sensitive to the Data Generating Process. In our study, we refer to econometric theory and focus on the statistics whose distribution is not affected by nuisance parameters, namely $D F_{\rho}^{*}, D F_{t}^{*}$ and $A D F_{t}$.

\section{C.2 The augmented regression in the ADF test}

We take another version of the cointegration test proposed by Kao which is a unit root test for the residuals $\widehat{e}_{i t}$ of the long run equation:

$$
\triangle \widehat{e}_{i t}=\Phi \widehat{e}_{i t-1}+v_{i t}
$$

with $H_{0}: \Phi=0$, which can be rewritten as:

$$
\begin{gathered}
\triangle\left(\tilde{Y}_{i t}-\tilde{X}_{i t}^{\prime} \widehat{\beta}\right)=\Phi\left(\widetilde{Y}_{i t-1}-\widetilde{X}_{i t-1}^{\prime} \widehat{\beta}\right)+v_{i t} \\
\Leftrightarrow \triangle\left(\widetilde{Y}_{i t}\right)=\Phi\left(\widetilde{Y}_{i t-1}-\widetilde{X}_{i t}^{\prime} \widehat{\beta}\right)+(\Phi+1) \triangle \widetilde{X}_{i t}^{\prime} \widehat{\beta}+v_{i t}
\end{gathered}
$$

To obtain the ADF statistic, the previous regression is augmented as:

$$
\begin{gathered}
\triangle \widehat{e}_{i t}=\Phi \widehat{e}_{i t-1}+\sum_{j=1}^{p} \varphi_{j} \triangle \widehat{e}_{i t-j}+v_{i t p}, \\
\Leftrightarrow \triangle\left(\widetilde{Y}_{i t}\right)=\Phi\left(\widetilde{Y}_{i t-1}-\widetilde{X}_{i t-1}^{\prime} \widehat{\beta}\right)+\triangle \widetilde{X}_{i t}^{\prime} \widehat{\beta}+\sum_{j=1}^{p} \varphi_{j} \triangle\left(\widetilde{Y}_{i t-j}-\widetilde{X}_{i t-j}^{\prime} \widehat{\beta}\right)+v_{i t p} \\
\Leftrightarrow \triangle\left(\widetilde{Y}_{i t}\right)=\Phi\left(\widetilde{Y}_{i t-1}-\widetilde{X}_{i t}^{\prime} \widehat{\beta}\right)+(\Phi+1) \triangle \widetilde{X}_{i t}^{\prime} \widehat{\beta}+\sum_{j=1}^{p} \varphi_{j} \triangle \widetilde{Y}_{i t-j}+\sum_{j=1}^{p}\left(-\varphi_{j}\right) \triangle \widetilde{X}_{i t-j}^{\prime} \widehat{\beta}+v_{i t p},
\end{gathered}
$$

which appears to be a constrained version of the regression implemented in the ARDL framework (see Regr. 2). 